\title{
Prevalence and Outcome of Abdominal Vascular Injury in Severe Trauma Patients - An International Registry Analysis
}

\author{
Mohammad Esmaeil Barbati ( $\square$ mbarbati@ukaachen.de) \\ Universitätsklinikum Aachen https://orcid.org/0000-0003-0709-8533
}

\section{Frank Hildebrand}

University Hospital Aachen: Universitatsklinikum Aachen

\section{Hagen Andruszkow}

University Hospital Aachen: Universitatsklinikum Aachen

\section{Rolf Lefering}

University of Witten/Herdecke: Universitat Witten/Herdecke

\section{Michael Jacobs}

University Hospital Aachen Department of Vascular Surgery

Houman Jalaie

University Hospital Aachen: Universitatsklinikum Aachen

\section{Alexander Gombert}

University Hospital Aachen: Universitatsklinikum Aachen

\section{Research}

Keywords: Abdominal vascular injury, Trauma registry, Polytrauma, Venous injury

Posted Date: April 26th, 2021

DOl: https://doi.org/10.21203/rs.3.rs-448222/v1

License: (c) (i) This work is licensed under a Creative Commons Attribution 4.0 International License. Read Full License 


\section{Abstract}

\section{Background}

Abdominal vascular injuries and the resulting hemorrhagic shock are still one of the main causes of death in trauma patients. This study details the etiology, frequency and effect of major vessel lesions of the abdomen in patients after polytrauma.

Patients and methods

All patients of TraumaRegister DGU® who met the following criteria were included: online documentation of European trauma centers, age 16-85 years, presence of abdominal vascular injury, and AIS $\geq 3$. Patients were divided in three groups based on the type of vessel injuries: arterial injury only, venous injury only, mixed arterial and venous injuries.

Results

A total of 2949 patients met the inclusion criteria. A blunt mechanism of abdominal vascular injuries was more frequent in all three groups. All types of vessel injuries were more prevalent in patients with relevant abdominal trauma followed by relevant thoracic trauma. On admission to hospital the rate of patients with shock were the same in patients with arterial injury alone $(n=606,33 \%)$ and venous injury alone $(n=95,32 \%)$. Patients with venous injury alone or together with arterial injuries had higher early (within first 24h) mortality rates (isolated arterial injury OR: 1.31; 95\%, CI 1.14-1.50, $\mathrm{p}<0.001$; isolated venous injury OR: $1.48 ; 95 \%, \mathrm{Cl} 1.10-1.98, \mathrm{p}=0.010$ ) and also in-hospital mortality.

\section{Conclusion}

Abdominal arterial injury and venous injury were equally responsible for the rate of hemodynamic instability at the time of admission. However, the proportion of adverse outcome during hospital stay was significantly higher in patients with venous injury. Stable patients suspected of abdominal vascular injuries should be further investigated to exclude or localize the possible retroperitoneal hematoma caused by subtle venous injury.

\section{Introduction}

Trauma-related abdominal vascular injuries are associated with a relevant mortality rate (1). Even in the setting of a Primary Trauma Center and after prompt diagnosis, abdominal trauma involving major vessel injury remains challenging to treat (2). Affected patients are very likely to require early and aggressive resuscitation measures in order to avoid or treat blood loss-associated acidosis, coagulopathy and hypothermia $(3,4)$. The relevance of aortic or iliac artery injury for patients' outcome after blunt and penetrating abdominal trauma has been well described (5). However, literature dealing with the impact of major venous vessel injury on patients' outcome after polytrauma is scarce. If available, the impact of abdominal major venous vessel injury is displayed in combination with aortic or iliac artery lesion (1). 
Outcome after isolated venous injury of all causes is directly related to a high mortality rate (6). Using the Europe-wide data assessment of the TraumaRegister DGU® we aimed to evaluate the impact of major abdominal vessel injury in severely injured polytrauma patients treated in primary trauma centers. Furthermore, the relevance of major venous vessel trauma and its impact on patients' survival could be analyzed for the first time in a multicentre registry setting.

\section{Materials And Methods}

In the present study, data is retrospectively analysed from the TraumaRegister DGU® (TR-DGU).

\section{Database}

The TraumaRegister DGU® of the German Trauma Society was founded in 1993. The aim of this multicentre database is a pseudonymised and standardized documentation of severely injured patients. Data are collected prospectively in four consecutive time phases from the site of the accident until discharge from hospital: A) Pre-hospital phase, B) Emergency room and initial surgery, C) Intensive care unit and D) Discharge. The documentation includes detailed information on demographics, injury pattern, comorbidities, pre- and in-hospital management, course on intensive care unit, relevant laboratory findings including data on transfusion and outcome of each individual. The inclusion criterion is admission to hospital via emergency room with subsequent ICU/ICM care or reach the hospital with vital signs and die before admission to ICU.

The infrastructure for documentation, data management, and data analysis is provided by AUC Academy for Trauma Surgery (AUC - Akademie der Unfallchirurgie $\mathrm{GmbH}$ ), a company affiliated to the German Trauma Society. The scientific leadership is provided by the Committee on Emergency Medicine, Intensive Care and Trauma Management (Sektion NIS) of the German Trauma Society (DGU). The participating hospitals submit their data pseudonymised into a central database via a web-based application. Scientific data analysis is approved according to a peer review procedure laid down in the publication guideline of TraumaRegister $D G U \circledast$. The participating hospitals are primarily located in Germany $(90 \%)$, but a rising number of hospitals of other countries contribute data as well (at the moment from Austria, Belgium, China, Finland, Luxembourg, Slovenia, Switzerland, The Netherlands, and the United Arab Emirates). Currently, almost 30,000 cases from more than 650 hospitals are entered into the database per year. Participation in TraumaRegister DGU® is voluntary. For hospitals associated with TraumaNetzwerk DGU®, however, the entry of at least a basic data set is obligatory for reasons of quality assurance.

The present study is in line with the publication guidelines of the TraumaRegister DGU $\circledast$ and registered as TR-DGU project ID 2018-027.

Data for the current research is obtained from TraumaRegister DGU® (TR-DGU) as a sizeable cohort in the period between 2002 and 2017. 
Patient selection was carried out according to the following criteria: (1) online documentation of European trauma centers since 2002, (2) age 16-85 years, (3) patients with serious injury (maximum Abbreviated Injury Scale $\geq 3$ ). Early transfer out patients (within 48 hours after admission) were excluded in order to avoid double counting from both hospitals. Patients with vascular injuries in the abdomen were divided in three groups based on type of abdominal vessel injuries: arterial injury only (Al), venous injury only $(\mathrm{VI})$, and mixed arterial and venous injuries (AVI). Patients without a vascular trauma in the abdomen served as control group. The Abbreviated Injury Scale (AIS) and Injury Severity Score (ISS) has been applied for injury grading (7). The updated Revised Injury Severity Classification score (RISC II) (8) was used to adjust the observed mortality rates.

All participating hospitals are classified as supra-regional (level 1), regional (level 2) or local (level 3) trauma centers based on the availability of human and technical resources (9). Organ failure was defined according to the Sequential Organ Failure Assessment (SOFA) where 3 or 4 points per organ was considered as organ failure. Multiple organ failure was defined as parallel failure of two or more organs for at least two days. Sepsis was defined according the ACCP/SCCM Consensus Conference (1992) as Systemic Inflammatory Response Syndrome (SIRS) plus a documented infection (10).

\section{Statistical Analysis}

Descriptive analysis was presented as number of cases with percentage for categorical variables and mean with standard deviation (SD) for continuous measurements. No imputation was performed for missing data; all results refer to valid entries only. The effect of vascular injury on outcome (hospital mortality) was evaluated with a logistic regression analysis. Other independent predictors in this analysis were the RISC II score (a combination of 15 predictive factors available on admission), massive transfusion, and hospital level of care. Results are presented as odds ratio (OR) with $95 \%$ confidence interval $(95 \% \mathrm{Cl})$. All analyses were performed using SPSS statistical software (version 24, IBM Inc., Armonk, NY, USA).

\section{Results}

Table 1 summarizes the study group's basic characteristics; abdominal vascular injury was present in 2949 patients ( $1.6 \%$ of all patients considered). Isolated arterial injury seen among $83.4 \%$ of these patients $(n=2459)$. There were 383 patients $(13 \%)$ admitted with isolated venous injury and 107 patients (3.6\%) had both arterial and venous injuries. Number of patients with ISS above 16 was $341(89 \%)$ in patients with VI, $2236(92 \%)$ in patients with $\mathrm{Al}$, and $98(92 \%)$ in patients with AVI. Blunt trauma was the most common mechanism responsible for abdominal vascular injuries in all three groups. Traffic injuries were common ( $n=1720,69.9 \%)$. Within the group of 230 assaulted patients, $179(77.8 \%)$ sustained stabbing injuries and $51(22.2 \%)$ patients had gunshot wounds. Out of the 2949 patients, $948(32.1 \%)$ were hemodynamically unstable at the time of admission. 
Table 1

Basic characteristics of 2949 patients with abdominal vascular injuries

\begin{tabular}{|c|c|c|c|}
\hline & $\begin{array}{l}\text { arterial injury } \\
\text { only } \\
n=2459\end{array}$ & $\begin{array}{l}\text { venous injury } \\
\text { only } \\
n=383\end{array}$ & $\begin{array}{l}\text { mixed arterial and venous } \\
\text { injuries } \\
n=107\end{array}$ \\
\hline Age (years)* & $48.7 \pm 19.1$ & $44.0 \pm 18.3$ & $43.8 \pm 17.6$ \\
\hline Males & $1831(75 \%)$ & 267 (70\%) & $83(78 \%)$ \\
\hline$I S S \geq 16$ & $2236(92 \%)$ & $341(89 \%)$ & $98(92 \%)$ \\
\hline ISS* & $33.8 \pm 15.6$ & $33.5 \pm 16.5$ & $35.9 \pm 15.5$ \\
\hline Penetrating trauma & $230(10 \%)$ & $58(16 \%)$ & $29(28 \%)$ \\
\hline $\begin{array}{l}\text { Prehospital shock } \\
\text { (syst. BP } \leq 90 \mathrm{mmHg} \text { ) }\end{array}$ & $606(33 \%)$ & $95(32 \%)$ & $37(47 \%)$ \\
\hline $\begin{array}{l}\text { Shock at ED admission } \\
\text { (syst. BP } \leq 90 \mathrm{mmHg} \text { ) }\end{array}$ & 777 (35\%) & $125(36 \%)$ & $46(47 \%)$ \\
\hline \multicolumn{4}{|l|}{ Mechanism of injury } \\
\hline $\begin{array}{l}\text { Traffic accident - } \\
\text { Car/lorry }\end{array}$ & $821(34 \%)$ & $120(32 \%)$ & $26(24 \%)$ \\
\hline $\begin{array}{l}\text { Traffic accident - } \\
\text { Motorcycle }\end{array}$ & $344(14 \%)$ & $58(15 \%)$ & $12(11 \%)$ \\
\hline Traffic accident-Bicycle & $96(4 \%)$ & $25(7 \%)$ & $5(5 \%)$ \\
\hline $\begin{array}{l}\text { Traffic accident - } \\
\text { Pedestrian }\end{array}$ & $167(7 \%)$ & $38(10 \%)$ & $8(8 \%)$ \\
\hline High Fall (>3 m) & $438(18 \%)$ & $47(13 \%)$ & $15(14 \%)$ \\
\hline Low Fall $(<3 \mathrm{~m})$ & $143(6 \%)$ & $14(4 \%)$ & $3(3 \%)$ \\
\hline Gunshot & $28(1 \%)$ & $13(3 \%)$ & $10(9 \%)$ \\
\hline Stabbing & $140(6 \%)$ & $28(7 \%)$ & $11(10 \%)$ \\
\hline ISS. Injury Severity Score & & & \\
\hline
\end{tabular}

The distribution of arterial and venous injuries in patients with relevant injuries (AIS $\geq 3$ ) of head, thoracic, abdomen and extremities are shown in Table 2. All types of vessel injuries were more prevalent in patients with relevant abdominal trauma followed by relevant thoracic trauma as the second most common cause. 
Table 2

Distribution of arterial and venous vessel injuries in patients with relevant injury (AIS $\geq 3$ )

\begin{tabular}{|c|c|c|c|c|}
\hline Affected vessel & $\begin{array}{l}\text { Relevant } \\
\text { head trauma } \\
n=84544\end{array}$ & $\begin{array}{l}\text { Relevant } \\
\text { thoracic } \\
\text { trauma } \\
n=91437\end{array}$ & $\begin{array}{l}\text { Relevant } \\
\text { abdominal } \\
\text { trauma } \\
n=25426\end{array}$ & $\begin{array}{l}\text { Relevant injury o } \\
\text { the extremities } \\
n=58555\end{array}$ \\
\hline $\begin{array}{l}\text { Abdominal vascular } \\
\text { injury }\end{array}$ & $825(0.9 \%)$ & $1980(2.1 \%)$ & 3425 (13.4\%) & $1640(2.8 \%)$ \\
\hline $\begin{array}{l}\text { Abdominal aortic or } \\
\text { arterial injury }\end{array}$ & $589(0.7 \%)$ & $1431(1.6 \%)$ & $2566(10.1 \%)$ & $1173(2.0 \%)$ \\
\hline $\begin{array}{l}\text { Abdominal venous } \\
\text { injuries }\end{array}$ & $117(0.1 \%)$ & $271(0.3 \%)$ & $466(1.8 \%)$ & $229(0.4 \%)$ \\
\hline Inferior vena cava & $48(<0.1 \%)$ & $107(0.1 \%)$ & $153(0.6 \%)$ & $67(0.1 \%)$ \\
\hline Iliac vein & $26(<0.1 \%)$ & $42(<0.1 \%)$ & $87(0.3 \%)$ & $84(0.1 \%)$ \\
\hline $\begin{array}{l}\text { Other abdominal } \\
\text { veins }\end{array}$ & $45(<0.1 \%)$ & $129(0.1 \%)$ & $153(0.6 \%)$ & $87(0.1 \%)$ \\
\hline
\end{tabular}

Patients with higher abdominal AIS were more unstable and required blood transfusion more frequently. In this subgroup of patients, rate of cessation of the trauma resuscitation algorithm and going under emergency surgery was higher with increasing abdominal AIS (Table 3).

Table 3

Early clinical management in subgroups according to severity of abdominal vascular trauma

\begin{tabular}{|lllll|}
\hline & Controls & AIS-3 & AIS-4 & AIS-5 \\
\hline No. of patients & 184276 & 1380 & 1323 & 211 \\
\hline Systolic BP $\leq \mathbf{9 0} \mathbf{m m H g}$ on admission & $16399(10 \%)$ & $316(25 \%)$ & $500(42 \%)$ & $120(64 \%)$ \\
\hline Blood transfusion & $22202(12 \%)$ & $530(39 \%)$ & $717(56 \%)$ & $133(66 \%)$ \\
\hline Massive transfusion & $3831(2 \%)$ & $185(14 \%)$ & $282(22 \%)$ & $56(28 \%)$ \\
\hline Number of pRBC & $0.7 \pm 3.1$ & $3.8 \pm 8.1$ & $6.3 \pm 10.8$ & $8.0 \pm 12.2$ \\
\hline Emergency surgery 1 & M: 0 & M: 0 & M: 2 & M: 4 \\
\hline Emergency surgery 2 & $2377(3 \%)$ & $87(13 \%)$ & $132(21 \%)$ & $24(24 \%)$ \\
\hline WB-MSCT & $40905(26 \%)$ & $605(51 \%)$ & $751(64 \%)$ & $132(71 \%)$ \\
\hline
\end{tabular}

Total numbers and percentages of each group are given with the total number of available datasets for each characteristic in parenthesis. 
Total patient numbers may vary for each procedure and characteristic because of incomplete data transmission or transmission of basic datasets. Basic datasets do not include information on emergency/early surgery.

Massive transfusion: $\geq 10$ units of packed red blood cells

Emergency surgery 1 : immediate surgery requiring cessation of the implemented trauma resuscitation algorithm (2002 until 2015); Emergency surgery2: Intervention (since 2009, from a list of 7 critical interventions, in the ER or directly consecutive)

BP: blood pressure, pRBC: packed red blood cells, M: median, WB-MSCT: whole-body multi-slice computed tomography

Patients with VI or AVI had higher mortality rates within the first $24 \mathrm{~h}$ as well as increased in-hospital mortality rates (Table 4). 
Table 4

Impact of venous injury on patient outcomes after abdominal trauma

\begin{tabular}{|llll|}
\hline & $\begin{array}{l}\text { only arterial } \\
\text { injury } \\
n=2459\end{array}$ & $\begin{array}{l}\text { only venous } \\
\text { injury } \\
n=383\end{array}$ & $\begin{array}{l}\text { both arterial and venous } \\
\text { injuries }\end{array}$ \\
\hline Mortality in first 24h & $448(18.2 \%)$ & $83(21.7 \%)$ & $35(32.7 \%)$ \\
\hline Hospital mortality & $689(28.0 \%)$ & $127(33.2 \%)$ & $47(43.9 \%)$ \\
\hline Multiple organ failure* & $648(47 \%)$ & $114(51 \%)$ & $37(65 \%)$ \\
\hline Sepsis* & $202(15 \%)$ & $31(14 \%)$ & $16(28 \%)$ \\
\hline Kidney failure* & $223(16 \%)$ & $34(15 \%)$ & $18(32 \%)$ \\
\hline Days of mechanical ventilation & $6.8 \pm 12.2$ & $6.5 \pm 11.4$ & $9.2 \pm 19.2$ \\
\hline ICU length of stay (day) & M: 1 & M: 1 & M: 1.5 \\
\hline Hospital length of stay & $11.6 \pm 15.9$ & $11.1 \pm 15.8$ & $16.3 \pm 29.7$ \\
\hline Blood transfusion & M: 5 & M: 5 & M: 3 \\
\hline $\begin{array}{l}\text { Massive transfusion ( } \geq 10 \text { units of } \\
\text { pRBC) }\end{array}$ & $24 \pm 26$ & $21 \pm 23$ & $27 \pm 38$ \\
\hline FFP transfusion & $396(16 \%)$ & $86(23 \%)$ & $46(44 \%)$ \\
\hline Average number of pRBC & $766(32 \%)$ & $144(38 \%)$ & $67(64 \%)$ \\
\hline * available only in patients with standard documentation $(68 \%$ of all cases)
\end{tabular}

Continuous variables presented with mean, SD, and median

Moreover, the rate of multiple organ failure, sepsis and kidney failure was higher in patients with VI or AVI. The mean hospital length of stay in patients suffering from AI, VI and AVI were 24, 21 and 27 days, respectively (Table 5). 
Table 5

Results of logistic regression analysis with in-hospital mortality as dependent variable

\begin{tabular}{|c|c|c|c|c|}
\hline Predictor & $\begin{array}{l}\text { Coefficent } \\
\text { (SE) }\end{array}$ & $\begin{array}{l}\mathrm{p}- \\
\text { value }\end{array}$ & $\begin{array}{l}\text { Odds Raio } \\
\text { (OR) }\end{array}$ & $\begin{array}{l}95 \% \text { confidence interval of } \\
\text { OR }\end{array}$ \\
\hline RISC II score & -0.96 & $<.001$ & 0.383 & $0.379-0.388$ \\
\hline \multicolumn{5}{|l|}{ Hospital level of care* } \\
\hline $\begin{array}{l}\text { regional trauma center } \\
\text { (level 2) }\end{array}$ & 0.04 & .094 & 1.04 & $0.99-1.10$ \\
\hline \multicolumn{5}{|l|}{ local trauma center (level 3) } \\
\hline $\begin{array}{l}\text { Arterial injury in the } \\
\text { abdomen } \star \star\end{array}$ & 0.43 & $<.001$ & 1.54 & $1.35-1.77$ \\
\hline $\begin{array}{l}\text { Venous injury in the } \\
\text { abdomen }{ }^{\star \star}\end{array}$ & 0.57 & $<.001$ & 1.77 & $1.33-2.36$ \\
\hline Constant term & -0.05 & .001 & & \\
\hline \multicolumn{5}{|c|}{ The analysis is based on 164,370 patients; Nagelkerke's $R^{2}=0.585$} \\
\hline \multicolumn{5}{|c|}{ * reference group: supra regional trauma center (level 1) } \\
\hline
\end{tabular}

Blood (BT) and fresh-frozen plasma (FFP) transfusion rate as well as rate of massive transfusion (MT) were higher in patients with VI compared to Al (BT: 201 (53\%) vs. 1120 (46\%), FFP: 144 (38\%) vs. 766 (32\%) and MT: $86(23 \%)$ vs. $396(16 \%)$ ) (Table 4).

A multivariable logistic regression model was calculated to evaluate the potential impact of abdominal vascular injury on mortality. Further independent predictors were the RISC II score, massive transfusion, and hospital level of care. In this analysis, isolated VI and isolated Al were significantly related with hospital mortality. Venous trauma showed higher odds ratio for in-hospital mortality (isolate Al: OR: 1.31; 95\% Cl 1.14-1.50, p < 0.001; isolated VI: OR: 1.48; 95\% Cl 1.10-1.98, p = 0.010) (Table 5).

\section{Discussion}

The mortality rate of severely injured persons is negatively influenced by the presence of a hemorrhagic shock that is mainly due to severe abdominal and pelvic trauma.

According to our data, road accidents account for most of the abdominal vascular injuries, followed by fall from heights as the second most important cause. Results from preceding studies indicated blunt trauma especially following road traffic accident is the main mechanism of abdominal vascular injuries in trauma patients $(11,12)$. Als are more common in this setting, yet Vls are also likely to occur (Table 2) and should not be underestimated (13). Inferior vena cava (IVC) injuries lead to high rates of morbidity and mortality. Studies reported that more than one-third of patients with an IVC injury has a mortality rate 
of more than $60 \%$ after admission to hospital $(14,15)$. Accordingly, hemodynamic status and prompt identification of bleeding source are in focus when treating patients suffering from abdominal vascular injuries (16). In the vast majority of cases, intraabdominal hemorrhage may lead to metabolic acidosis followed by coagulopathy and hypothermia, the so-called lethal triad of trauma $(17,18)$.

In terms of the diagnosis of abdominal vascular injuries, preoperative assessment of hemodynamically unstable patients may include Focused assessment with sonography for trauma (FAST) or diagnostic peritoneal lavage to confirm the hemoperitoneum $(19,20)$. However, retroperitoneal injuries have no or just a small volume of free blood. Significant retroperitoneal VIs, such as those affecting the retrohepatic IVC, can be subtle, with patients presenting with no symptoms at all, or even with intermittent hypotension that reacts to resuscitation at the beginning. Asensio et al. reported 275 retroperitoneal hematoma in 302 patients with abdominal vessel injuries for an incidence of 91\% (1). Concerning the rapid diagnosis of retroperitoneal injuries it is advocated that in stable patients suspected of abdominal vascular injuries, a triple-contrast abdominal CT scanning may be beneficial to localize the retroperitoneal vascular injuries and evaluate the extension of vessel involvement $(21,22)$.

Although in current study the rate of hemodynamic instability at the time of admission was the same in patients with VI (36\%) comparing to patients with $\mathrm{Al}(35 \%)$, the rate of adverse outcome was significantly higher in patient with VI. Based on the present data, an increase in mass transfusion and multiple organ failure correlated significantly with involvement of Vls in patient suffering from abdominal vascular injuries. Consecutively, an increase in mortality rates within the first 24 hours and during the hospital stay can be assessed after VI or AVI (Tables 1 and 4).

In the present study, the overall mortality rate was $29.2 \%$, reflecting a high mortality associated with abdominal vascular injuries as reported in other studies (17-54\%) $(1,12,23-26)$. Number of factors predicting mortality in abdominal vascular injuries have been described before, i.e., the presence of shock, hypothermia, acidosis, dysrhythmias, transfusion requirement, and number of injured vessels $(24,26-$ 29). Our results after adjusting the mortality for covariates, showed that the $\mathrm{VI}$ is associated with significantly increased odds of mortality (OR: $1.48 ; 95 \% \mathrm{Cl} 1.10-1.98, \mathrm{p}=0.010)$. This effect was even higher than abdominal $\mathrm{Al}(\mathrm{OR}: 1.31 ; 95 \% \mathrm{Cl} 1.14-1.50, \mathrm{p}<0.001)$. The mortality rates in patients with $\mathrm{VI}$ was higher compared with $\mathrm{Al}(21.7 \%$ vs. $18.2 \%$ in first 24 hours, $33.2 \%$ vs. $28 \%$ in hospital mortality, respectively) (Table 4$)$.

The shortcomings of the study are by far similar to other studies using large registry databases. TR-DGU's initial aim was to register severely injured patients or those with multiple injuries and solely require ICU admission. It only includes in-hospital trauma fatalities, excluding victims that died at scene or during transport. Lack of follow-up outcomes for the included patient variables may have impacted both the univariate and modelling results.

\section{Conclusion}


Abdominal $\mathrm{VI}$ are present in $25-28 \%$ of all patients with abdominal vascular injury due to traumatic events of different body region. Patients with $\mathrm{VI}$ showed a more distinct decrease in survival rate after hospital admission and increased duration of hospital stay. Stable patients suspected for abdominal vascular injuries should undergo further scanning to investigate and localize the possible retroperitoneal hematoma caused by subtle VI.

\section{Declarations}

\section{Ethical Approval and Consent to participate}

The present study is in line with the publication guidelines of the TraumaRegister DGU® and is registered as TR-DGU Project ID 2018-027. As register data are assessed anonymously, individual informed consent is not required.

\section{Consent for publication}

N/A.

\section{Availability of supporting data}

The datasets used and/or analyzed during the current study are available from the corresponding author on reasonable request.

\section{Competing interests}

The authors declare that they have no competing interests.

\section{Funding}

This manuscript was prepared without any external funding.

\section{Authors' contributions}

MB designed the study together with $A G$, interpreted the data with $H J$ and drafted the manuscript. RL provided the database for analysis and performed the statistical calculations. In repeated discussion rounds, $M B, H J, A G$ and $F H$ checked its clinical relevance. Furthermore, important contributions to the discussion section were made by HJ, MJ, FH, HA and RL. All authors were involved in the critical appraisal of the draft version, and they all read and approved the final manuscript. 


\section{Acknowledgements}

Special thanks go to the IFOM Institute and Prof. Rolf Lefering for their outstanding support. We would like to thank the TraumaRegister-DGU of the German Trauma Society for their support.

\section{References}

1. Asensio JA, Chahwan S, Hanpeter D, Demetriades D, Forno W, Gambaro E, et al. Operative management and outcome of 302 abdominal vascular injuries. Am J Surg. 2000;180(6):528-33. discussion $33-4$.

2. Brenner M, Hicks C. Major Abdominal Trauma: Critical Decisions and New Frontiers in Management. Emerg Med Clin North Am. 2018;36(1):149-60.

3. Cirocchi R, Montedori A, Farinella E, Bonacini I, Tagliabue L, Abraha I. Damage control surgery for abdominal trauma. Cochrane Database Syst Rev. 2013(3):CD007438.

4. Adnan SM, Anderson RG, Madurska MJ, McNeill CJ, Jansen JO, Morrison JJ. Outcomes following abdominal trauma in Scotland. Eur J Trauma Emerg Surg. 2019.

5. Joseph B, Zeeshan M, Sakran JV, Hamidi M, Kulvatunyou N, Khan M, et al. Nationwide Analysis of Resuscitative Endovascular Balloon Occlusion of the Aorta in Civilian Trauma. JAMA Surg. 2019.

6. Kakkos SK, Tsolakis IA, Markopoulos G, Maroulis I, Koletsis E, Fligou F, et al. Presentation patterns and prognosis of 109 isolated venous injuries in 99 patients. Phlebology. 2019:268355519837870.

7. Gennarelli TA, Wodzin E. AIS 2005: a contemporary injury scale. Injury. 2006;37(12):1083-91.

8. Lefering R, Huber-Wagner S, Nienaber U, Maegele M, Bouillon B. Update of the trauma risk adjustment model of the TraumaRegister DGU ${ }^{\mathrm{T}}$ : the Revised Injury Severity Classification, version II. Crit Care. 2014;18(5):476-.

9. Ruchholtz S, Lewan U, Debus F, Mand C, Siebert H, Kuhne CA. TraumaNetzwerk. DGU((R)): optimizing patient flow and management. Injury. 2014;45(Suppl 3):89-92.

10. Bone RC, Sibbald WJ, Sprung CL. The ACCP-SCCM consensus conference on sepsis and organ failure. Chest. 1992;101(6):1481-3.

11. Yasuhara H, Naka S, Kuroda T, Wada N. Blunt thoracic and abdominal vascular trauma and organ injury caused by road traffic accident. Eur J Vasc Endovasc Surg. 2000;20(6):517-22.

12. Heuer M, Hussmann B, Kaiser GM, Lefering R, Paul A, Lendemans $S$, et al. Abdominal vascular trauma in 760 severely injured patients. Eur J Trauma Emerg Surg. 2013;39(1):47-55.

13. Graham JM, Mattox KL, Beall AC. Jr. Portal venous system injuries. J Trauma. 1978;18(6):419-22.

14. Netto FA, Tien H, Hamilton P, Rizoli SB, Chu P, Maggisano R, et al. Diagnosis and outcome of blunt caval injuries in the modern trauma center. J Trauma. 2006;61(5):1053-7.

15. Vaidya SS, Bhargava P, Marder CP, Dighe MK. Inferior vena cava dissection following blunt abdominal trauma. Emerg Radiol. 2010;17(4):339-42. 
16. Asensio JA, Chahwan S, Hanpeter D, Demetriades D, Forno W, Gambaro E, et al. Operative management and outcome of 302 abdominal vascular injuries. The American Journal of Surgery. 2000;180(6):528-34.

17. Ganter MT, Pittet JF. New insights into acute coagulopathy in trauma patients. Best Pract Res Clin Anaesthesiol. 2010;24(1):15-25.

18. Stone HH, Strom PR, Mullins RJ. Management of the major coagulopathy with onset during laparotomy. Ann Surg. 1983;197(5):532-5.

19. Radwan MM, Abu-Zidan FM. Focussed Assessment Sonograph Trauma (FAST) and CT scan in blunt abdominal trauma: surgeon's perspective. Afr Health Sci. 2006;6(3):187-90.

20. Fleming S, Bird R, Ratnasingham K, Sarker S-J, Walsh M, Patel B. Accuracy of FAST scan in blunt abdominal trauma in a major London trauma centre. Int J Surg. 2012;10(9):470-4.

21. Vu M, Anderson SW, Shah N, Soto JA, Rhea JT. CT of blunt abdominal and pelvic vascular injury. Emergency radiology. 2010;17(1):21-9.

22. Mullins RJ, Huckfeldt R, Trunkey DD. Abdominal vascular injuries. Surg Clin North Am. $1996 ; 76(4): 813-32$.

23. Sorrentino TA, Moore EE, Wohlauer MV, Biffl WL, Pieracci FM, Johnson JL, et al. Effect of damage control surgery on major abdominal vascular trauma. J Surg Res. 2012;177(2):320-5.

24. Eachempati SR, Robb T, Ivatury RR, Hydo LJ, Barie PS. Factors associated with mortality in patients with penetrating abdominal vascular trauma. J Surg Res. 2002;108(2):222-6.

25. Davis TP, Feliciano DV, Rozycki GS, Bush JB, Ingram WL, Salomone JP, et al. Results with abdominal vascular trauma in the modern era. Am Surg. 2001;67(6):565-70. discussion 70 - 1.

26. Tyburski JG, Wilson RF, Dente C, Steffes C, Carlin AM. Factors affecting mortality rates in patients with abdominal vascular injuries. J Trauma. 2001;50(6):1020-6.

27. Asensio JA, Britt LD, Borzotta A, Peitzman A, Miller FB, Mackersie RC, et al. Multiinstitutional experience with the management of superior mesenteric artery injuries. J Am Coll Surg. 2001;193(4):354-65. discussion $65-6$.

28. Jackson MR, Olson DW, Beckett WC Jr, Olsen SB, Robertson FM. Abdominal vascular trauma: a review of 106 injuries. Am Surg. 1992;58(10):622-6.

29. Collins PS, Golocovsky M, Salander JM, Champion H, Rich NM. Intra-abdominal vascular injury secondary to penetrating trauma. J Trauma. 1988;28(1 Suppl):165-70. 